\title{
Remarks on Income Contingent Loans: How Effective can they be at Mitigating Risk?
}

Joseph E. Stiglitz

Columbia University, USA

\subsection{ICL and risk}

A well-known principle holds that equity provides better risk sharing opportunities than debt, but that there are greater enforcement problems associated with equity. Income contingent loans (ICL) represent an efficient (low transactions cost) way of implementing equity contracts for human capital. ${ }^{1}$ The amount the individual repays is dependent on his or her income. While it seems natural to link ICL with investments that increase the value of human capital - most notably education - there is no necessary reason to limit it to such investments.

The limits on market provision of ICL are related to: (a) enforcement costs; (b) adverse selection; and (c) moral hazard. Government provision lowers transactions costs because of the joint product of income reporting for purposes of the income tax. But reporting is imperfect, and the higher the effective tax rate (including the fraction of income committed in ICL repayments), the greater the incentive for underreporting. In some areas and in some countries, this is greater than others. This likely imposes an upper bound to the extent to which there can be reliance on ICL. For a country like the US where a large fraction of transactions are electronic and where top income tax rates are low, the scope for vastly expanded use of ICL would seem large.

Adverse selection effects can be serious, which is why ICL needs to be focused on areas where forced pooling (so those that rationally anticipate having high incomes don't drop out of the program ${ }^{2}$ ) seems plausible, such as 
higher education. But can the old way of financing education through public funding also be thought of as a form of ICL? Individuals can be thought of as paying for their education retroactively, by giving the government a (large) share of their incremental income. There is a distinction: those who did not go to college pay as well as those that do. This, then, is the critical distinction in effect, a higher tax rate for those who avail themselves of a college education than those that do not. But, of course, efficient investment requires that individuals pay for the costs of education. The risk sharing associated with ICL should lead to more investment in education than would be the case under current arrangements, even if individuals are not capital constrained. Given the large benefits - non-pecuniary as well as monetary - to a college education, the underinvestment (if any) in education for those who have sufficient wealth is likely to be small.

But for those who do not have funds of their own, risk sharing is important. They have to borrow, and with conventional loans, were they to pay the full costs of a college education, their level of indebtedness would be very high. If their income turned out to be low, the consequences for their living standards would be very adverse. The realization of this would inhibit undertaking a college education, even if the expected returns exceeded the costs by a substantial amount. There would be significant underinvestment in education. ${ }^{3}$

In a world in which everyone went to colleges costing the same amount, a comprehensive ICL in which everyone had to participate would be little different (apart from the intergenerational issues to be noted below) from public funding. ICL typically entails a linear relationship between repayment and income, and most countries have adopted slightly progressive tax systems, but in principle, there is nothing to restrict ICL to linear schedules. (In fact, various provisions in most ICL programs - for example, forgiveness of the residual debt after a certain number of years - do make the repayment function non-linear.) If almost everyone went to colleges costing the same amount, would there be any point of having a separate ICL program? Would it be simpler to provide a tax rebate to the few people who did not go to college? (The optics of rewarding people for not going to college might not be so positive, but functionally, it does not appear to be different from taxing those who do.)

Adverse incentive effects are likely to be small, so long as income tax rates and ICL repayment rates combined are not too large. But in countries with already high income tax rates, the marginal disincentive effect will have to be considered. There are a large number of decisions that may be affected by the implicit tax associated with ICL: labor supply, retirement, job choice (including risk taking), compensation packages (with repayments limited to twenty years, there is an incentive for hard-to-value deferred compensation schemes). So long as the ICL repayment percentage is relatively low, the magnitude of these effects will be limited.
A standard objecti so high, why doesn retorts: first, there a through the income may not be possibl government is purst different from that function, for instanc cannot be pooling in

Most importantly, and (if there is an in if government were ts with conventional lo willing to borrow. A equality of opportuni borne by the individu:

However, there are insurance and loan externalities. For inst to repay other loans. these externalities. government programs. severe with a conventi harder (reducing unem unemployment insuras have a lower reservatic into the economic syst accrue to the governm private lender would $n$ should lend to an ind available.

There are, of course, of opportunity and acc public provision of edu by many countries. It 1 self-selection: those $\mathrm{w}$ education will not choo education has consum excessive consumption. by screening.

Probably more impo economies driven by $\mathrm{m}$ there is a concern abo 
tion through public an be thought of as vernment a (large) ose who did not go ritical distinction elves of a college nvestment requires sharing associated would be the case capital constrained. tary - to a college r those who have

haring is important. they to pay the full uld be very high. If eir living standards hibit undertaking a ed the costs by a ment in education. ${ }^{3}$ the same amount, a ate would be little noted below) from between repayment ressive tax systems, schedules. (In fact, forgiveness of the ake the repayment s costing the same program? Would it d not go to college? ye might not be so it from taxing those

as income tax rates ut in countries with ffect will have to be $y$ be affected by the ement, job choice gayments limited to erred compensation relatively low, the
A standard objection to government loan programs is that, if the returns are so high, why doesn't the private market provide the funds? There are two retorts: first, there are significant economies of scope in collection, arising through the income tax system. What is easy and feasible for the government may not be possible or be expensive for the private sector; second, the government is pursuing a social welfare maximization objective markedly different from that of the private sector. With a utilitarian social welfare function, for instance, pooling is socially efficient and desirable. But there cannot be pooling in a private market economy.

Most importantly, government is concerned with equality of opportunity and (if there is an inequality-averse social welfare function) of income. Even if government were to make funds available to anyone who wanted to borrow, with conventional loans, many of those from poor families would not be willing to borrow. As a result, society would be afflicted with a low level of equality of opportunity. ICL loans change all of this, because now, the risk borne by the individual is reduced to a more manageable level.

However, there are further market failures associated with private sector insurance and loan programs, especially associated with cross-market externalities. For instance, greater student indebtedness may affect the ability to repay other loans. Government programs can be designed to be sensitive to these externalities. Furthermore, there are externalities to numerous government programs. Because the consequences of not having a job are more severe with a conventional loan, an individual who has lost his job may search harder (reducing unemployment insurance payments, with benefits both to the unemployment insurance fund and to the government's Treasury), but may have a lower reservation wage in accepting a job - introducing an inefficiency into the economic system. Some of the benefits of a more educated labor force accrue to the government, in the form of higher tax revenues. Obviously, a private lender would not include these benefits in the calculus of whether he should lend to an individual and the terms at which he would make loans available.

There are, of course, other ways that social objectives of enhancing equality of opportunity and access to education can be achieved, in particular through public provision of education. This is a route that has traditionally been taken by many countries. It has two disadvantages. The first is that ICL facilitates self-selection: those who do not expect to get sufficient returns out of education will not choose to get a college or advanced education. Especially if education has consumption value, then with free education there will be excessive consumption. Efficiency will require a greater burden being borne by screening.

Probably more important, however, are the fiscal realities, in political economies driven by myopic governments (and the citizens who elect them): there is a concern about budget deficits even if the spending is used to 
increase assets, enhancing the economy's productivity and future tax revenues. Few governments have capital accounts which would help citizens assess the extent to which greater indebtedness is incurred to finance consumption or investment. Pressures to keep taxes and debts low mean that public financing of higher education cannot be relied upon. The overall national level of indebtedness is, of course, the same whether the government borrows to finance education, or if individuals borrow. Indeed, there can be distinct advantages to the latter, for borrowing costs are likely to be far lower (partly because of the lower transactions costs alluded to earlier in this note). ${ }^{4}$ Nonetheless, the desire to move the indebtedness off of the government's balance sheet onto private individual's balance sheets has had probably more to do with the reliance on student debt for financing higher education than anything else.

\subsection{Seeing ICL within a broader set of capital instruments}

Stiglitz and Yun (2013; Chapter 16, this volume) consider a set of instruments that provide societal risk sharing for individuals who have large adverse shocks, but not for small shocks (loans that are, effectively, forgiven in the event of extended unemployment). Let $R$ be the repayment as a function of lifetime income $Y$. The simplest ICL has $R=a Y$. But a more general scheme is $R=F(Y)$. For example,

$$
R=\left\{\begin{array}{l}
R^{*} \text { if } Y>Y^{*} \\
a Y \text { if } Y<Y^{*}
\end{array}\right.
$$

where $R^{*}=a Y^{*}$, or,

$$
R=\left\{\begin{array}{c}
a(Y-d) \text { if } Y>d \\
0 \text { if } Y<d
\end{array}\right.
$$

Different payments schemes will have different incentive and implementation (compliance) costs and, if there is not universal compulsion to join the scheme, different adverse selection effects. An important research question is to assess the relative merits of alternative repayment functions, under alternative assumptions.

If we have a situation where there is a well-defined income tax system, given by $T=T(Y, G)$ for every level of $G$, then if there is a group of individuals who are provided with additional benefits costing $\Delta G$ (in the simplest case, the entire population), and it is determined that they should be self-financed, then the repayment function for the program should presumably be:

$$
R(Y, G, \Delta G) \equiv
$$

The full analysis complicated. Here,

Those at th and/or goo increased $r$ some progr If there is $s$ generating improving occupations 1998).

Fixed oblig especially because the such indivic - and the a lower incon adverse inc programs $\mathrm{x}$ below a crit

It will be importan that is, should there education program, that income is low individual should counterfactual of wh been in the absence $c$ good at assessing the

\subsection{ICL as an inst protection}

The reason that ICI obviously cannot fin broader need for inte to make investments temporary loss in in 
nd future tax revenues. elp citizens assess the lance consumption or that public financing rall national level of vernment borrows to there can be distinct to be far lower (partly earlier in this note). ${ }^{4}$ of the government's as had probably more higher education than

\section{truments}

ler a set of instruments to have large adverse tively, forgiven in the rment as a function of a more general scheme

erent incentive and universal compulsion to An important research e repayment functions,

ed income tax system, if there is a group of its costing $\Delta G$ (in the ned that they should be ram should presumably

$$
R(Y, G, \Delta G) \equiv T(Y, G+\Delta G)-T(Y, G) .
$$

The full analysis of the shape of the optimal repayment function is quite complicated. Here, I suggest three considerations: ${ }^{5}$

(i) Those at the top receive disproportionately large amounts from rents and/or good luck, so that the adverse incentive effects of marginally increased recoupment rates will be small. There should be at least some progressivity in the repayments schedule.

(ii) If there is some complementarity across skills - those in certain areas generating higher productivity for lower wage workers, and thus improving the before-tax distribution of income - tax rates in such occupations may be lower than they otherwise would be (see Stiglitz, 1998).

(iii) Fixed obligations at the bottom can have strong incentive effects, especially if there is a stigma associated with bankruptcy. But because the revenue raised is small (unless there are large numbers of such individuals) and the suffering of these individuals is significant - and the anticipation of such suffering may be a large deterrent to lower income individuals undertaking education, and so has strong adverse incentive effects on education - it seems preferable to have programs which entail total debt forgiveness when income falls below a critical threshold.

It will be important to assess whether there is a need for better screening that is, should there be full reliance on self-selection into the ICL loan/tertiary education program, or whether there should be admissions officers. The fact that income is low even with a college education does not mean that the individual should not have gone to school; we have to assess the counterfactual of what his income (and broader life satisfaction) would have been in the absence of the school. It may be, however, that individuals are not good at assessing these private and social returns.

\subsection{ICL as an instrument for investment in the young and social protection}

The reason that ICL is a natural fit for education is that young people obviously cannot finance their own investments in education. But there is a broader need for intertemporal smoothing, borrowing younger in life in order to make investments that yield a return later in life or to smooth out a temporary loss in income (as a result of a bout of unemployment) or a 
temporary increase in income needs (such as might arise in the event of an illness, in the presence of imperfect disability insurance.)

As Stiglitz and Yun (2013; Chapter 16, this volume) point out, the need for smoothing through loans depends on the extent to which there is insurance (which smoothes income across states of nature). Moral hazard and adverse selection arise in both loans and insurance, and there are important crossmarket externalities. Even in the limited case of a market characterized by a single set of risks (unemployment in different periods) solving for the optimal mix of insurance and loans turns out to be inordinately complicated.

Given the importance of human capital (for most individuals early in their life, it represents the predominant form of wealth), the benefits of better ways of sharing the risks associated with human capital should be obvious. This is especially so in the context of individuals undertaking fixed large obligations today for payments in the future. Thus, if an individual faces a short bout of unemployment early on in life, the impact on his or her lifetime income will be negligible, and a conventional loan (perhaps collateralized by future retirement benefits) has the advantage of having no adverse incentive effects. In such a situation, the benefits of risk mitigation from an ICL are negligible, and (at least in standard models) would be outweighed by the adverse incentive effects (though these could be small). But the problem is that the future is uncertain: there is uncertainty about whether an individual who faces a short bout of unemployment today will face further bouts in the future, to such an extent that the repayment of a loan today would impose hardship later in life. Income contingent loans are a good way of handling such uncertainty.

The liabilities that are encountered in paying for tertiary education are not small; nor are those that might be encountered as part of extended periods of unemployment or disability, or other temporary but large needs associated with child rearing. One could imagine extending ICL to any of these arenas. Questions, however, arise:

(i) As the obligations increase, so too do the adverse incentive effects (both adverse effects on generating income and on reporting income). Is there a threshold above which we should become worried?

(ii) In the case of tertiary education, it is relatively easy to force a pooling equilibrium. In the case of other areas, this may be more difficult. (If ICL were part of an unemployment scheme, high income individuals might claim to not be unemployed, so as not to be forced to participate; they can easily create low income generating consultancy firms.) Without pooling, ICL can still work, but it would serve a limited group of high risk/highly risk averse individuals.

(iii) As the domain of activities covered increases and the size of the ICL program(s) increase, there can be important interactions (externalities) with other activities. Stiglitz and Yun (2013; Chapter 16, this

volum unemp undert into a emplo unemp

This raises tl alternative vari incentive and $\mathrm{s}$ example, Singa different kinds incentive effect that characteriz forces pooling a

\subsection{Transitior}

Consider a stan generation pays a large transfer 0 just, because wh $t-1$. But now, $c$ each generation 1 from its parents, Any notion of $\mathrm{i}$ unfair', unless, generation $t+1 \mathrm{i}$ as many countrie fully funded prog generation is bein for their own retir

How particular shifts of burdens that should be add benefits of these 1 worth the costs.

\section{Notes}

1. For a review of th volume), Chapman 
n the event of an

out, the need for here is insurance zard and adverse important crossaracterized by a $g$ for the optimal icated.

als early in their ts of better ways obvious. This is large obligations $s$ a short bout of ime income will lized by future ncentive effects. $\mathrm{L}$ are negligible, by the adverse blem is that the vidual who faces in the future, to se hardship later ch uncertainty. ducation are not ended periods of heeds associated of these arenas.

incentive effects porting income). rorried?

force a pooling tore difficult. (If ome individuals 0 be forced to ting consultancy would serve a als.

size of the ICL ons (externalities) hapter 16, this volume), for instance, focus on the effect on job search of unemployment compensation; but they note that individuals may undertake excessive precautionary savings, because they do not take into account the adverse effect of such savings on search and employment, with implications in turn for the costs of the unemployment insurance system.

This raises the further question: are there institutional designs (including alternative variants of the repayment function) which mitigate the adverse incentive and selection effects? Which lead to less adverse externalities? For example, Singapore's Provident Fund (allowing spreading of risks across different kinds of shocks) may allow better risk mitigation without adverse incentive effects than the separate funds (unemployment, disability, retirement) that characterize the dominant forms of social protection. Such a system forces pooling across these risks.

\subsection{Transition}

Consider a standard overlapping generations life cycle model, where each generation pays for the education of its children. In effect, generation $t$ makes a large transfer of wealth to generation $t+1$. In a steady state, they feel this is just, because when they were young, they received a transfer from generation $t-1$. But now, consider what happens if we change the system to one where each generation pays for its own education. Now, generation $t$ received a gift from its parents, but does not bequeath the same gift onto its descendants. Any notion of intergenerational equity would say such a redistribution is 'unfair', unless, that is, generation $t$ made an offsetting larger transfer to generation $t+1$ in a different form. But something like that may be happening: as many countries switch from pay-as-you go social insurance programs to fully funded programs (or at least more fully funded programs), the current generation is being asked both to pay for their parent's retirement and to pay for their own retirement.

How particular members of each generation are affected by these complex shifts of burdens and responsibilities across generations is an important issue that should be addressed in future research - as is the question of whether the benefits of these large intertemporal shifts in burdens and responsibilities are worth the costs.

\section{Notes}

1. For a review of the basic economics of ICL see Chapman (2010; and Chapter 1, this volume), Chapman and Hunter (2009), and Quiggin (Chapter 3, this volume). 
2. Pooling refers to individuals of different characteristics (different future income profiles) being within the same program. As we note below, ICL can be thought of a loan program plus an insurance program for those whose income turns out to be low, financed by those whose income turns out to be high. But in markets, those who know that their income is likely to be high will attempt to 'separate' themselves out, so that the premium they would have to pay for this income insurance is reduced. That is why there may have to be forced pooling.

3. In most countries, bankruptcy laws provide for some risk sharing; those whose incomes are very low can get a fresh start. But so-called bankruptcy reform in the US has made it almost impossible to discharge student debt, increasing the consequences of adverse outcomes and further discouraging investments in education.

4. Moreover, from a social point of view, the risks are the same, except with public finance there is de facto better risk pooling. Securitization of student loans has increased the extent of risk pooling; but the US mortgage crisis has highlighted fundamental problems with securitization, including the role of ratings agencies in assessing the risks associated with various financial products and the limitations of the abilities of the rating agencies and distortions in their incentives.

5. The similarity between this and the standard optimal tax problem should be obvious. Here, we are maximizing a social welfare function aggregating expected utilities of different individuals, where individuals may differ in both their abilities and idiosyncratic risks, and where they are making decisions not just about labor supply, but about education and jobs.

\section{References}

Chapman, B. (2010) 'Policy Design Issues for Risk Management: Adverse Selection and Moral Hazard in the Context of Income Contingent Loans', in G. Marston, J. Moss and J. Quiggin (eds) Risk, Welfare and Work (Carlton, Australia: Melbourne University Press) pp. 233-252.

Chapman, B and B. Hunter (2009) 'Exploring creative applications of income contingent loans', Australian Journal of Labour Economics, Vol. 12, No. 2, pp. 133-144.

Stiglitz, J.E. (1998) 'Pareto Efficient Taxation and Expenditure Policies, With Applications to the Taxation of Capital, Public Investment, and Externalities', presented at conference in honor of Agnar Sandmo, Bergen, January 1998.

Stiglitz, J.E. and J. Yun (2013) 'Optimal Provision of Loans and Insurance Against Unemployment From A Lifetime Perspective', National Bureau of Economic Research Working Paper No. w19064.

\section{3}

\section{Income $\mathrm{Co}$ Manageme}

\author{
John Quiggin \\ University of Queensland
}

This chapter presents that, under plausible market loans under as In particular, if indiv labor participation d additional unit of incor the period in which contingent loan is imp the repayment period effects on labor supply for wages in the int schedule would lead to

\subsection{Introduction}

Beginning in Australi: used in a number of financing. The Austral Contribution Scheme (1 undergraduate universi adopted in several o concerning their pos replacements for tradit 2003) has recommende capacity to efficiently c 